\section{REVISTA BRASILEIRA DE QUALIDADE DE VIDA}

\title{
Políticas Públicas e Esporte: a contribuição da Qualidade de Vida nesta relação
}

\section{Sports and Public Policy: the contribution of quality of life in this relationship}

\author{
Marco Antonio Bettine de Almeida \\ Escola de Artes, Ciências e Humanidades - Universidade de São Paulo - USP - São Paulo - Brasil \\ marcobettine@usp.br \\ Gustavo Luis Gutierrez \\ Faculdade de Educação Física - Universidade Estadual de Campinas - UNICAMP - Campinas - Brasil \\ glgutierrez@terra.com.br
}

\begin{abstract}
Resumo
Este artigo fará uma relação entre qualidade de vida e políticas públicas de esporte. A qualidade de vida compreendida enquanto a expectativa de melhoria e transformação das condições concreta de existência das pessoas. $\mathrm{O}$ esporte como fenômeno que possui distintas dimensões e alto impacto nas políticas públicas, suas intervenções deveriam relacionar a cultura e o esporte, pois, muitas das atividades designadas esporte passam por manifestações de cultura. Conclui-se que os gestores e profissionais deveriam pensar suas ações como totalidade de um sistema histórico voltando-se para: (a) qualificação profissionais para a promoção de atividades esportivas próprias para os objetivos de cada manifestação, (b) processo de comunicação positivo entre promotor da prática e praticantes, (c) comprometimento político em projetos horizontais e longitudinais, (d) valorizar o esporte enquanto elemento importante na formação social e cultural.
\end{abstract}

Palavras-chave: esporte, política pública, qualidade de vida.

\begin{abstract}
This article makes a connection between quality of life and public policies for sport. The quality of life understood as the expectation of improvement and transformation of the concrete conditions of existence of people. The sport as a phenomenon that has different dimensions and high impact on public policies, their speeches should relate to culture and sport, because many of the sports activities are designated by expressions of culture. It is concluded that the managers and professionals should consider their actions as a whole system back up history to: (a) professional qualification for the promotion of sports activities suitable for the purpose of each event, (b) the communication process between positive promoter of the practice and practitioners, (c) political commitment on projects horizontal and longitudinal, (d) enhance the sport as an important element in shaping social and cultural.
\end{abstract}

Keywords: sport, public policy, quality of life.

\section{Introdução}

Este artigo procura desenvolver uma reflexão a respeito das políticas públicas de esporte a partir da discussão atual sobre qualidade de vida. Acredita-se importante e urgente desenvolver esta 
relação entre esporte e qualidade de vida, no sentido de construir pontes e aproximações úteis para a reflexão a respeito do tema.

Como se apontou em um texto anterior (ALMEIDA; GUTIERREZ; MARQUES, 2009), a qualidade de vida constitui-se enquanto objeto de pesquisa de forte vocação multidisciplinar. Isto significa dizer que há no seu interior a soma das dificuldades metodológicas, teóricas e políticas dos diferentes campos de estudo que contribuem para a sua formação. Neste sentido é fundamental ter presente na análise da qualidade de vida a sua dimensão política, compreendida enquanto a expectativa de melhoria e transformação das condições concreta de existência das pessoas.

Neste artigo pensar-se-á o esporte como possibilidade de transformação da vida das pessoas. Desde a carta constitucional de 1988 o esporte passa a ser parte de programas de Estado, colocado em um mesmo patamar de importância que outras esferas sociais, como o trabalho, a saúde ou a moradia. Neste sentido, fortalecer as políticas públicas de esporte é oferecer elementos para melhorar as condições de vida e estilo de vida das pessoas.

Neste texto, alertar-se-á os gestores para pensar as políticas públicas não somente como acesso ao esporte, mas sim possibilitar que os programas estatais transformem o estilo de vida das pessoas.

Programas como, Descoberta do Talento Esportivo; Bolsa Atleta; Segundo Tempo; Pintando a Liberdade; Esporte e Lazer na Cidade; são intervenções que nos seus objetivos, segundo leitura do site do Ministério do Esporte, oferecem melhorias nas condições de vida da população, porém sem uma perspectiva de transformação do estilo de vida, ou mesmo proposta para as pessoas o acessarem.

Ao exemplificar algumas ações Federais do Ministério do Esporte buscou-se não a crítica aos programas, mas sim, oferecer mais um objeto de reflexão que é também pensar a intervenção no movimento e no esporte pautado na discussão multidisciplinar de qualidade de vida. Este artigo procurará debater estas questões, primeiramente fortalecendo os conceitos de qualidade de vida, posteriormente de políticas públicas para ao final relacionar as políticas públicas de esporte com os conceitos de qualidade de vida. No próximo item discutir-se-á o método de pesquisa.

\section{Método de Pesquisa}

Nas próximas páginas analisar-se-á as políticas públicas de esporte e a possível relação com a qualidade de vida, tendo como método a interpretação de documentos e de literatura temática nos seguintes tópicos: qualidade de vida, políticas públicas e esporte.

Todos estes temas não serão pensados como mera soma de descrições de experiências ou acontecimentos. Serão sistematizados no conjunto das pesquisas em ciências humanas, destacando seus atores fundamentais, permitindo ultrapassar o simples senso comum. A base teórica para a interpretação destes documentos parte da percepção de um sujeito da ação social que busca racionalmente fins objetivos. As instituições envolvidas serão estruturadas a partir do conceito de tipo ideal weberiano (WEBER, 1994), que consiste em exagerar e formar um entendimento comum do objeto para possibilitar interpretações sobre sua importância no cenário mais amplo. Os tipos ideais serão: (1) a qualidade de vida, entendida como acesso aos bens materiais (Condições de Vida) e transformar a forma das pessoas viverem (Estilo de Vida); (2) a política pública entendida como ação estatal dirigida à população para a subordinação das pessoas de um território promovendo condutas e à dominação ordeira por parte dos participantes, podendo utilizar da força física estatal como parte do processo de racionalização das condutas sociais; (3) o esporte compreendido como sistematização dos movimentos e das regras dos jogos populares, transformando-os em modalidades que possuem uma organização rígida que busca o confronto de pessoas, ou grupos de pessoas, para fins competitivos, com o objetivo último de obter a vitória.

Todos estes tipos têm como pressuposto a inter-relação da política, da competição, da sistematização e da racionalização. Sua utilização enquanto recurso de apoio epistemológico permitirá analisar as políticas públicas no esporte com base nos conceitos de qualidade de vida. 
Importante lembrar que o esporte possui esta inserção na política pública devido também a "esportivização da sociedade". Este fator proporcionou uma educação voltada à busca dos talentos, do vencedor e da necessidade da prática do esporte para o bem-estar. O esporte, devido a este fenômeno, estudado em outro texto (ALMEIDA; GUTIERREZ; MARQUES, 2009), garantiu um posto privilegiado perante os programas governamentais, tido como uma possibilidade de esporte de massa, formação de cidadãos, transmissão de valores de competição e busca por crescimento, representatividade nacional e a forma de expressar o país como uma grande nação em desenvolvimento.

Todo este processo levou à democratização do esporte e do exercício físico. Às novas formas de intervenções profissionais, preocupadas com a participação, acrescenta-se também uma preocupação social com a saúde, desvinculando-se do conceito de saúde como ausência de doença, frente à idéia de saúde como sinônimo de qualidade de vida.

Finalmente, cabe colocar que o texto a seguir procura traçar uma síntese das relações entre esporte e qualidade de vida, desde a perspectiva da inserção no campo das políticas, procurando contribuir para desenvolver e aprofundar uma reflexão abrangente a respeito das diferentes dimensões que influenciam as condições das práticas esportivas e a sua preocupação com a qualidade de vida.

\section{Fortalecendo os conceitos}

O termo qualidade de vida nos leva a desenvolver um processo amplo de pensar a saúde a partir de argumentos macro-sociais. Oferecer as condições materiais não é suficiente. Quando temos uma longa história de exclusão torna-se necessário um amplo processo educativo e de políticas públicas para saber utilizar os bens que são oferecidos, isto é, não bastam programas, mas sim ensinar como acessá-los.

A noção de qualidade de vida transita em um campo semântico e polissêmico: de um lado, está relacionada ao modo, condições e estilos de vida. De outro, inclui as idéias de construção humana e valores socialmente constituídos. E, por fim, relaciona-se ao campo da democracia, do desenvolvimento e dos direitos humanos e sociais. No que concerne à saúde, as noções se unem em uma resultante social da construção coletiva dos padrões de conforto e tolerância que determinada sociedade estabelece, como parâmetros, para si (ALMEIDA; GUTIERREZ; MARQUES, 2009, p.17).

Pensar qualidade de vida é relacionar a noção, o entendimento e a construção histórica, com os sentimentos psíquicos da população na vida familiar, amorosa, social e ambiental. O conteúdo social, relacional e cultural que envolve desde o acesso aos bens materiais até o uso destes bens. Perceber os significados da qualidade de vida é o compreender como construção cultural.

A cultura, no sentido mais amplo, integra-se em diferentes mecanismos de ação que perpassam o universo simbólico no qual o agente vive, onde o corpo é o primeiro filtro da percepção seja por meio dos sentidos, ou compreendido como experiências. Cultura no sentido estrito é entendida pela busca individual de elementos cotidianos para a formação do homem enquanto agente histórico.

Neste sentido Elias aponta para uma idéia de civilização representada por uma coletividade que define certos padrões, mas que inserido nesta totalidade o indivíduo procura na sua cultura formas múltiplas de relacionamento no pensar e agir (ELIAS, 1984, p.68).

Para entender os programas de qualidade de vida a partir do seu componente cultural, devese ter o cuidado de não atribuir aos programas uma incorporação das ações culturais pura e simplesmente. Porque há a cultura de massa que os programas de qualidade de vida deveriam evitar para não ser apenas um veículo de reprodução cultural e, sim, de transformação social.

Bosi (1986) atenta para o caráter dominante da cultura de massa. Nesta interpretação, a partir de leituras de Adorno e Horkheimer (1986), a crise da cultura leva a concepção de cultura de massa, sendo uma nova era para a cultura: "claramente não folclórica; abertamente organizada por 
empresários da indústria; fortemente estruturada em função de um certo público-massa e necessariamente distinta das experiências social" (BOSI, 1986, p.73). Além dele, outros autores (MORIN, 1997; ADORNO; HORKHEIMER, 1986; BENJAMIM, 1994) acusam a cultura de massa de não ser cultura, mas indústria, de não ser orgânica, mas exterior e manipuladora da inteligência e sensibilidade. Morin aborda esta perda de sensibilidade denominando-a "segunda industrialização", a ser a industrialização do espírito (MORIN, 1997). "É esse o caso daquilo que pode ser considerado uma Terceira Cultura, oriunda da imprensa, do cinema, do rádio, da televisão, do esporte que surge, desenvolve-se, projeta-se, ao lado das culturas clássicas e nacionais" (MORIN, 1997, p.14).

Apesar da qualidade de vida ter seu componente cultural importante, ela não se confundiu com cultura de massa, pelo contrário, seu conceito e sua atuação buscam a mudança de estilo de vida das pessoas estruturado pela indústria cultural.

Política pública, entendida a partir do conceito de Max Weber, é processo de racionalização da organização ou do sistema social. Pode-se dizer que se, para Weber (1994), o desenvolvimento de todas as formas de organização social estava associado a processos de racionalização, isto é verdade também para o que ele chamava de políticas públicas, as quais, na nossa contemporaneidade, se expressam na forma das ações estatais.

Em Economia e Sociedade, obra que reúne suas principais contribuições teóricas conceituais, Weber apresenta a seguinte definição para a noção de comunidade política: "uma comunidade cuja ação social é dirigida para a subordinação de um território e da conduta das pessoas dentro dele à dominação ordeira por parte dos participantes, através da disposição de recorrer a força física, incluindo normalmente a força das armas" (1978, p. 901). Além de dominar um território e de manter o controle sobre a conduta de seus habitantes, mesmo que tenha que fazer uso da força física para tal, uma comunidade política se caracterizaria ainda pela capacidade de regulação das interações entre seus membros, em sentido amplo, não se restringindo às ações ou práticas sociais voltadas apenas para a realização de seus interesses econômicos (WEBER, 1994, p. 902). Na mesma direção, a referência ao caráter ordeiro da dominação chama atenção para a importância do reconhecimento da autoridade ou da legitimidade das relações de poder constituídas. Em outras palavras, as comunidades políticas se caracterizariam também pelo cultivo de valores e peculiaridades culturais partilhadas entre seus habitantes (por exemplo, símbolos nacionais), assim como pelo sentimento de solidariedade e, porque não, por uma identidade compartilhada por meio do esporte, no caso brasileiro o futebol.

Contudo, o processo de racionalização das instituições políticas provocou um distanciamento de tal ordem entre a ação política e as formas de vida, que tornou difícil concebê-las como comunidades políticas em termos weberianos. Isto é, como unidades políticas que tenham uma identidade cultural definida. Portanto, as políticas públicas refletem mais interesses subjetivos e de poder do que necessidades da população.

Habermas (1987) afirma que é difícil visualizar como os cidadãos se sentem representados nas instituições políticas de suas sociedades, ou como poderiam internalizar alguma concepção de dever cívico, exclusivamente através de uma cultura política ou de uma constituição que se mantém absolutamente impermeáveis aos valores cultivados nos grupos ou comunidades de referência onde os cidadãos se reconhecem não apenas como indivíduos, mas também enquanto pessoas dignas e merecedoras de consideração, portadoras de uma substância moral e de uma identidade própria.

Para que uma identidade se institua como tal, mesmo que tenha um caráter abrangente como aquela associada à noção de patriotismo constitucional, é necessária que aqueles que com ela se identificam tenham a legitimidade de suas identidades locais (culturais, regionais, étnicas e que representante e representado sejam mutuamente reconhecidos).

Neste sentido, o esporte pode ser um veículo importante que poderá minimizar este afastamento, articulando as formas de vida específicas, as demandas com as políticas públicas de esporte. 
Neste contexto a discussão do esporte como política pública é particularmente interessante, na medida em que deveria agregar a afirmação de valores universais (vida, saúde, bem-estar, cidadania, respeito, legalidade, participação política) com uma preocupação em relação ao respeito de grupos multiculturais (folclore, raça, gênero, etnia, hábitos, costumes, necessidade especial e faixa etária).

\subsection{Esporte como possibilidade de política pública}

A passagem do século XX, no Esporte, para o século XXI foi marcada por um quadro conceitual amplo de mudanças e tendências influenciadas pelas transformações sociais e políticas (LUCENA, 2001), principalmente com o fim da guerra fria, a globalização e a importância da atividade física no mundo contemporâneo.

Desde os jogos olímpicos modernos de Pierre de Coubertin o Esporte se transformou, podese afirmar que o universo dividido em esportes amadores e profissionais tornou-se mais complexo que a simples aferição de renda. Hoje o esporte, como fenômeno social, possui distintas dimensões (ALMEIDA; GUTIERREZ, 2009, p.1).

Depois da Segunda Guerra Mundial, o quadro internacional do Esporte transformou-se em todas as suas formas e pode-se afirmar que uma interpretação correta do conjunto de fatos históricos tornou-se extremamente difícil.

O Esporte ganha uma nova forma, o ensino de suas práticas para uma educação do Movimento. $\mathrm{O}$ aspecto pedagógico incorporou o ensino técnico da modalidade como espelho direto do fenômeno esportivo como universalização da prática.

No esporte, as alterações da segunda metade do século XX, pós-guerra, foram profundas, pois o número de praticantes e modalidades cresceu impressionantemente. Além disso, o esporte era visto apenas na perspectiva do rendimento e após a Carta Internacional de Educação Física e Esporte da UNESCO em 1978, a prática esportiva, passou a ser entendida como "direito de todas as pessoas".

A idéia de uma prática esportiva pluralista trouxe a possibilidade de democratização e dissociação do esporte e atleta profissional. A abrangência social do Esporte passou a ser preponderante. As formas de exercício do direito ao Esporte passaram a ser o educacional, o popular/lazer, o alto-rendimento e o de massa. Estas dimensões do conceito contemporâneo de Esporte podem ser explicadas da seguinte maneira:

a) Educacional pelos princípios sócio-educativos da participação, cooperação, co-educação, inclusão e do desenvolvimento do espírito esportivo;

b) O popular/lazer pela tradição, princípio da não obrigatoriedade, adaptação para a participação de todos e preocupação com os valores culturais do jogo e do esporte;

c) O alto-rendimento, pelos princípios da superação, competição, performance e uso de diferentes tecnologias;

d) O de massa, pela indústria do entretenimento, consumo de bens materiais, reprodução do movimento e busca de uma estética pré-determinada.

Cabe lembrar que a globalização transformou o esporte principalmente com os avanços tecnológicos como o uso de mídias para o ensino tático e técnico; novos materiais como fibra de carbono; nutrição; psicologia; os diferentes tipos de doping; aspectos financeiros como motor exclusivo da prática; perda da relação entre o atleta e o país de origem.

Na mundialização cultural o esporte se integra ao meio social conforme suas dimensões e características locais. O Esporte de Rendimento Profissional é aquele que pelo fenômeno da secularização, igualdade, especialização, racionalização, burocracia, quantificação e recorde integra uma realidade cultural sem sofrer adaptações, uma competição mundial na China, por exemplo, é a mesma dos Estados Unidos, independente do modelo econômico, cultural e social destes e de outros países. Mostrando que o esporte burocratizado estrutura- 
se em um todo coeso e justamente esta coesão é que o possibilitou se tornar um fenômeno mundial (ALMEIDA; GUTIEERREZ, 2009, p.1).

O esporte passa a ser movimento de massa devido ao investimento econômico no setor e ampliação do mercado consumidor. Outro ponto a ser lembrado sobre a massificação do esporte é que a partir da ampliação dos praticantes aumentou-se o investimento do Estado levando a uma transformação no conceito de planejamento urbano e de políticas públicas no setor. $\mathrm{O}$ próprio desenvolvimento na área científica demonstrou um avanço no entendimento do esporte nas escolas juntamente com a prática das modalidades.

\begin{abstract}
Neste sentido, é razoável defender a idéia de que o esporte participação como cultura espelha mais a sociedade atual do que a prática de alguns escolhidos geneticamente para representar o país como monocultura. Porém, o esporte participação necessita de um espelho, algo para mimetizar e isto é oferecido pela espetacularização, por meio da sua beleza, arte, integração e plasticidade. As imagens veiculadas ao esporte, bem como um aparato midiático de grande proporção leva a alimentação do sentido da participação da prática, e quanto mais pessoas colocam o esporte no seu cotidiano mais espetacularizado ele fica. Este processo histórico, complexo, oferece uma pequena base para entender a esportivização da sociedade e, como ela está presente na vida das pessoas, simbolizando competição, originalidade, beleza, frustração, vitória, reciprocidade ou alegria, tornando as relações sociais repletas de valores esportivos (ALMEIDA; GUTIERREZ, 2009, p.21).
\end{abstract}

Na questão referente do acesso ao esporte percebemos a prática não sistematizada e a falta de locais para que o esporte se desenvolva, bem como uma falta de estrutura dos esportes amadores, ficando apenas algumas modalidades eleitas que dão retorno midiático.

Avançando as discussões anteriores sobre o esporte, hoje se pode afirmar que ele possui distintas dimensões, conforme a definição esporte de massa, popular/lazer, alto-rendimento e educacional. As políticas públicas deveriam intervir na dimensão:

a) Do alto-rendimento (investimento em locais, estruturas, atletas, treinadores, clubes e na ciência do treinamento);

b) Educativa, (projetos nas escolas, campeonatos escolares, professores, profissionais na área de saúde, ensino do movimento somado às modalidades, financiamento de estudos na área da pedagogia do movimento e do esporte e intervenção voltada ao aluno);

c) Popular/lazer (praças de esporte e de lazer, recursos humanos, formação humanista voltado à saúde, projeto urbanístico, projetos sociais para pessoas em estado de vulnerabilidade, projetos para grupos especiais e projetos para formação cidadã). $\mathrm{O}$ esporte de massa já possui uma inserção na vida das pessoas e um alto grau de influência, portanto, não deveria haver, em um primeiro momento, investimentos públicos neste setor.

Nas dimensões de (a) a (c), as intervenções deveriam relacionar a cultura e o esporte, pois, muitas das atividades designadas esporte passam por manifestações de cultura. Os jogos, as brincadeiras podem ser consideradas práticas para o ensino de alguma modalidade esportiva e fazem parte da herança cultural de cada comunidade. Procurando não segmentar nem a idéia de esporte, e nem tampouco a de cultura, os gestores e profissionais deveriam pensar suas ações como totalidade das tradições, técnicas e instituições derivadas de um sistema histórico, parte integrante e indissociável do saber partilhado por determinada comunidade.

O cuidado que os programas de políticas públicas no esporte, pensados a partir dos conceitos de qualidade de vida, deveriam ter é afastar-se da influência da cultura de massa (MORIN, 1997). Estudiosos deste período, como Benjamin (1994), Adorno e Horkheimer (1986), discutiram a influência deste movimento cultural no cotidiano da sociedade industrial, apontando para seu caráter dominador e ideológico, principalmente pela criação de mecanismos de difusão em massa, como é o caso do rádio, da fotografia, cinema e televisão. Neste caso o esporte, que anteriormente se expressava no seio da cultura, agora divulga a rapidez e o consumo. Os meios de comunicação terminam por substituir outras formas de expressão não consumistas, isto é, apresentam-se enquanto 
mercadoria, e disseminando hábitos e costumes, e moldando relações interpessoais (CORBIN, 1995).

Estes processos de substituição foram construídos para desenvolver o consumo e expandir o novo sistema de produção, num processo de padronização da vida enquanto modelo a ser seguido, atingindo diretamente as modalidades esportivas. No esporte ocorrem os dois processos apontados anteriormente, (a) a mecanização das modalidades esportivas através da incorporação da tecnologia e (b) a substituição prática esportiva não-consumista por uma necessidade de consumo, por meio da ideologização. Nesta perspectiva de análise a cultura de massa, pelo processo de substituição e ideologização, pode ser percebida subordinando todas as outras expressões em prol do consumo, para constituir-se enquanto campo hegemônico.

Quadro 1: Características do esporte no campo de atuação

\begin{tabular}{|c|c|c|c|c|}
\hline $\begin{array}{l}\text { DIMENSÕES } \\
\text { ESPORTIVAS }\end{array}$ & Alto-Rendimento & Educacional & Popular/lazer & Massa \\
\hline $\begin{array}{c}\text { Atributos } \\
\text { sociais } \\
\text { valorizados }\end{array}$ & $\begin{array}{c}\text { Performance } \\
\text { Profissionalismo } \\
\text { Vencedor }\end{array}$ & $\begin{array}{c}\text { Autoconhecimento } \\
\text { Individualidade } \\
\text { Subjetivismo }\end{array}$ & $\begin{array}{c}\text { Familiaridade } \\
\text { Coletivismo } \\
\text { Intersubjetivismo }\end{array}$ & $\begin{array}{c}\text { Alienação } \\
\text { Individualismo } \\
\text { Economia }\end{array}$ \\
\hline $\begin{array}{c}\text { Relação com as } \\
\text { políticas } \\
\text { públicas }\end{array}$ & $\begin{array}{c}\text { Pouco } \\
\text { investimento, } \\
\text { cabendo aos } \\
\text { clubes de modo } \\
\text { geral o patrocínio, } \\
\text { ou empresas } \\
\text { privadas ou de } \\
\text { capital misto }\end{array}$ & $\begin{array}{l}\text { Poucos projetos e } \\
\text { investimento. } \\
\text { Ações isoladas e } \\
\text { falta de } \\
\text { continuidade }\end{array}$ & $\begin{array}{c}\text { Vários Programas } \\
\text { Federais sem apoio } \\
\text { popular }\end{array}$ & $\begin{array}{c}\text { Bastante } \\
\text { investimento } \\
\text { (exemplo do futebol) } \\
\text { Garimpo de votos } \\
\text { Populista } \\
\text { Consumista }\end{array}$ \\
\hline $\begin{array}{c}\text { Relação com o } \\
\text { lazer }\end{array}$ & $\begin{array}{l}\text { Apenas para o } \\
\text { espectador } \\
\text { Lazer passivo } \\
\text { Espelho que se } \\
\text { reproduz em } \\
\text { outros campos }\end{array}$ & $\begin{array}{c}\text { Componente } \\
\text { lúdico das aulas }\end{array}$ & $\begin{array}{l}\text { Idéia de passadismo } \\
\text { Nostalgia romântica } \\
\text { Busca por jogos e } \\
\text { folclore }\end{array}$ & Quase sinônimo \\
\hline $\begin{array}{c}\text { Dificuldade ao } \\
\text { acesso }\end{array}$ & $\begin{array}{c}\text { Investimento } \\
\text { Público } \\
\text { Qualificação } \\
\text { Ampliar programa } \\
\text { nacional de } \\
\text { investimento no } \\
\text { atleta e } \\
\text { treinadores } \\
\end{array}$ & $\begin{array}{l}\text { Profissionais não } \\
\text { preparados } \\
\text { Escolas sem locais } \\
\text { adequados }\end{array}$ & $\begin{array}{c}\text { Dominação da } \\
\text { cultura urbano- } \\
\text { industrial } \\
\text { Falta de locais } \\
\text { Falta de divulgação } \\
\text { dos projetos }\end{array}$ & $\begin{array}{c}\text { Acesso aos bens } \\
\text { materiais }\end{array}$ \\
\hline Inserção social & $\begin{array}{c}\text { Poucas } \\
\text { modalidades com } \\
\text { inserção social } \\
\end{array}$ & Popular & Regionalista & $\begin{array}{l}\text { Dominação } \\
\text { Hegemônica }\end{array}$ \\
\hline $\begin{array}{l}\text { Formas de } \\
\text { expressão }\end{array}$ & $\begin{array}{l}\text { Desempenho } \\
\text { Performance }\end{array}$ & $\begin{array}{c}\text { Plural } \\
\text { Educativa } \\
\text { Participativa } \\
\end{array}$ & $\begin{array}{c}\text { Patriarcal } \\
\text { Coletivista } \\
\text { Identidade nacional } \\
\end{array}$ & $\begin{array}{c}\text { Mercadológica } \\
\text { Alienante } \\
\text { Massa consumidora } \\
\end{array}$ \\
\hline $\begin{array}{c}\text { Diálogo com } \\
\text { outros campos }\end{array}$ & Fechado & Aberto & Aberto & Fechado \\
\hline
\end{tabular}

As relações entre esporte e suas formas de manifestação, ou ainda a percepção das dimensões do esporte a partir da reflexão a respeito das suas políticas, permitem perceber a dominação (não absoluta) da indústria cultural, definida a aqui enquanto categoria próxima ao esporte de massa. Com relação ao esporte popular/lazer e o esporte educacional são caracterizados pela sociabilidade espontânea, autoconhecimento, apresentam um intercâmbio constante, ou pelo menos uma dimensão comum enquanto resistência ou re-significação do esporte de massa. $\mathrm{O}$ esporte de alto-rendimento possui uma inserção própria, ele vem da cultura popular por meio dos jogos e brincadeiras sistematizadas nas escolas inglesas, posteriormente, após a segunda Guerra mundial o esporte ganha relevância na sociedade urbano-industrial, incorporando os aspectos educacionais no ensino da técnica, para em seguida transformar-se em objeto de educação, levando 
os sentidos de patriotismo, higienismo e respeito. $\mathrm{O}$ avanço da indústria cultural em todos os campos sociais, como parte da mundialização, transformou a prática como algo ligado a economia perdendo toda a relação com o popular/lazer, educacional, conforme procurou ilustrar o quadro 1.

\subsection{Políticas públicas de esporte: relação qualidade de vida e esporte}

O investimento no esporte é uma opção política forte. O primeiro aspecto que chama a atenção, a partir desta linha de raciocínio, é o caráter educativo das políticas públicas de esporte. Como em gestões de diferentes prefeituras como Belo Horizonte (1999) e Rio Grande do Sul (STIGGER, 1996). O esporte se potencializa na educação pelo esporte, isto é, ao colocar o caráter educativo, as atividades esportivas são explicáveis e justificáveis. O programa federal Segundo Tempo é um exemplo desta tentativa do esporte como veículo de educação. Em outras palavras, o esporte apóia-se no processo pedagógico formal para fundamentar-se em algo maior e ter assim sua legitimação enquanto política pública. Outra alternativa, de valorização do esporte, passa por associá-lo ao controle da criminalidade (NICHOLLS, 1997). Trata-se então de um esporte funcionalista, que serve para minimizar os riscos sociais, fundamentado na concepção de que as ações ilícitas são provocadas por escolhas do indivíduo e não por problemas sociais mais gerais. $\mathrm{O}$ esporte é visto como integrante de um plano geral que vai eliminar a delinqüência (BH. Prefeitura Municipal, 1999).

A política pública de esporte, como qualquer outro setor, deve ter uma postura crítica e articular-se, compartilhando objetivos e recursos, além de adotar como critérios fundamentais o incentivo à sociabilidade espontânea e o desenvolvimento da sensibilidade e do autoconhecimento dos participantes. É neste sentido que se procurou apontar a importância da pesquisa a respeito do objeto qualidade de vida e sua contribuição para pensar o esporte e suas políticas.

A qualidade de vida no esporte se potencializaria na educação social da população e na busca constante pela cidadania. Em outras palavras, o caráter educativo e pedagógico justifica a inserção da qualidade de vida nas políticas públicas, já que a condição de vida e estilo de vida são fatores primordiais para o avanço global da sociedade.

A implementação de uma política de qualidade de vida dá-se no interior de um projeto político mais amplo, por meio de uma máquina de administração pública. As dificuldades são enormes, pois o controle de uma verba para ser distribuída, associa-se formação de grupos que irão compor uma base de apoio, levando às ações administrativas não coordenadas e independentes umas das outras. Assim, é extremamente difícil articular as propostas do campo da qualidade de vida com as de outras áreas como saúde, habitação, educação, pensando-as globalmente (ALMEIDA; GUTIERREZ, 2004).

Apesar deste contexto, as pesquisas e ações de qualidade de vida no esporte estudam as relações sociais presentes no ambiente esportivo e as conseqüências destas na vida das pessoas, tornando-se necessário um entendimento acerca das formas de comunicação e relacionamento existentes nesse meio. Ao desenvolver um programa de ensino das modalidades esportivas é preciso considerar não somente os benefícios fisiológicos do mesmo, mas também buscar atender a outros níveis de exigência do ser humano. Tais níveis dizem respeito às necessidades de relacionamento, bem-estar e auto-estima. As estratégias utilizadas para a promoção de bem-estar, manutenção da saúde, integração social e uma identificação maior das pessoas com a sociedade que a cerca. A prática esportiva se apresenta como uma dessas possibilidades, pois o esporte é um fenômeno social que além de incentivar o movimento, promove interação social e influencia no relacionamento e nas formas de comunicação entre os participantes.

Uma política pública de esporte com referência na qualidade de vida, portanto, deve estar voltada tanto para melhores condições e acesso as práticas esportivas, quanto para uma intervenção no cotidiano para que as pessoas percebam e valorizem o movimento em suas vidas.

A prática esportiva pautada em estruturas do esporte popular/lazer, educacional sugere ações cooperativas em suas atividades, visto que o objetivo é promover um processo de atividade esportiva independente da nomeação de melhores ou piores, vencedores e perdedores. Convém 
observar que nesse tipo de atividade podem também ocorrer ações competitivas, visto que a competição é intrínseca ao esporte e, em alguns casos, como os esportes coletivos, por exemplo, existe a necessidade da presença de um oponente para a realização da prática.

Neste momento os princípios da Qualidade de Vida, da prática Esportiva e da intervenção do profissional de Educação Física se encontram. O objetivo da qualidade de vida é o oferecimento de melhores condições de vida e a possibilidade de utilização destes recursos pelos sujeitos, transformando seu estilo de vida. O fenômeno esportivo, pensado como prática de grande aceitação social e com um alto potencial de intervenção, permite ser direcionado para melhoria das condições de vida e do estilo de vida. A Educação Física, com seu conteúdo pedagógico, pode fazer a intermediação com estudos sobre importância do movimento para diferentes grupos sociais, além de formar profissionais comprometidos com os objetivos dos programas de qualidade de vida.

Para que esta proposta tenha sucesso é necessário, em primeiro lugar, a presença de profissionais qualificados para a promoção de atividades esportivas próprias para os objetivos de cada manifestação, pois a simples aplicação de atividades não se faz suficiente. Segundo, é necessário, para um processo de comunicação positivo entre promotor da prática e praticantes, que haja um conhecimento a respeito de valores transmitidos pelo esporte e seus significados. Terceiro, haver um comprometimento político em projetos horizontais e longitudinais, do que verticais e pontuais. Último, valorizar o esporte enquanto elemento importante na formação social e cultural.

\section{Considerações Finais}

O campo da Qualidade de Vida, tanto no sentido da pesquisa teórica como enquanto alternativa de iniciativas e intervenções concretas, apresenta grandes desafios. É uma área em construção que depende, para seu desenvolvimento, do diálogo entre diferentes correntes e tradições acadêmicas. Além disso, é também um espaço de disputa e embate político, apropriado pelo dia da gestão pública, caracterizada pelo conflito entre diferentes atores e partidos políticos.

Suas dificuldades são proporcionais às suas possibilidades para auxiliar o processo de construção de condições de vida mais justa, sadias e felizes para amplos segmentos da sociedade. A questão da qualidade de vida não pode ser pensada isolada, nem do desenvolvimento científico, e nem tampouco das lutas políticas, econômicas e culturais que a rodeiam. Neste contexto, a interface com a reflexão sobre o Esporte e as diferentes formas de apropriação de sua prática pode contribuir de forma positiva.

A discussão a respeito de políticas de esporte pautada na qualidade de vida é complexa, um primeiro aspecto essencial discutido foi o seu caráter dúplice. A qualidade de vida no esporte deveria ser vista como melhoria do estilo de vida e condições de vida. Associar as políticas públicas a esta ordem é muito complicado já que as ações, segundo Almeida e Gutierrez (2004), priorizam a mudança subjetiva no estilo de vida, sem dar suporte material suficiente para ter condição de vida digna. Esta visão da qualidade de vida pode ser percebida em projetos federais de 2003-2006 como Mexa-se, Segundo Tempo, Esporte Lazer na Cidade e Política Nacional Contra o Diabetes, que propõem ações particularizadas sem proporcionar um pensamento articulado entre os diversos setores sociais (ALMEIDA; GUTIERREZ, 2007).

O conteúdo polissêmico do objeto qualidade de vida e suas políticas, acrescentado ao fato da construção de grupos de pesquisa, possibilitaram o fortalecimento da área do Esporte e da Educação Física nos conteúdos e nas intervenções dos projetos de qualidade de vida. O Esporte e a Atividade Física (pensados pelos princípios pedagógicos da Educação Física), portanto, passaram de meras ações pontuais, para estudos profundos dos aspectos positivos do movimento na vida das pessoas, pensando como mudança de Estilo de Vida e melhorias nas Condições de Vida.

Mas este processo, da atividade física e do esporte passar de meros objetos de programas para sujeitos, não será tranqüilo, muitos embates e debates serão necessários, para vencer o dualismo entre as teorias pedagógicas e a ciência biomédica.

O esporte pelo conceito de condições de vida pode ser pensado como o oferecimento para a população de práticas esportivas, em ambientes saudáveis, promovendo a saúde, o bem estar, o 
contato com o maior número de modalidades, ações voltadas para o movimento no sentido amplo, sociabilidade espontânea (MARQUES; GUTIERREZ; ALMEIDA, 2008), o estreitamento dos laços na comunidade, presença do poder público nestes locais e possibilitar a formação de sociedade civil organizada para gerir conjuntamente ao poder público por meio de diálogo a própria prática, transformando os programas de condições de vida para estilo de vida.

\section{Referências}

ADORNO, T.; HORCKEIMER, M. Dialética do esclarecimento, industria cultural: o esclarecimento como mistificação das massas. Rio de Janeiro: Zahar, 1986. Tradução: Guido de Almeida.

ALMEIDA, M.; GUTIERREZ, G. Políticas Públicas de lazer e qualidade de vida: a contribuição do conceito de cultura para pensar as políticas de lazer. In: VILARTA, R. (Org.). Qualidade de vida e políticas públicas: saúde, lazer e atividade física. Campinas: IPES Editorial, 2004. p.67-84

ALMEIDA, M.; GUTIERREZ, G. Índices de qualidade de vida no Brasil: instrumento para análise dos indicadores e das políticas públicas. Revista Gestão Industrial, v.3, n.3, ago./out. 2007, p.148159.

ALMEIDA, M.; GUTIERREZ, G. Esporte e sociedade. Lecturas, Educación Física y Deportes. v. 14, n. 133, jun. 2009.

ALMEIDA, M.; GUTIERREZ, G.; MARQUES, R. Qualidade de vida como objeto de estudo polissêmico: contribuições da Educação Física e do Esporte. Revista Brasileira de Qualidade de Vida. v. 01, n. 01, jan./jun. 2009, p. 15-22.

PREFEITURA MUNICIPAL DE BELO HORIZONTE. Secretaria Municipal de Esportes. O Lúdico e as políticas públicas: realidade e perspectivas. BH: PBH/SMES, 1999.

BENJAMIN, W. Magia e técnica, arte e cultura: ensaios sobre a literatura e história da cultura. São Paulo: Brasiliense, 1994. Tradução: Sergio Paulo Rouanet.

BOSI, E. Cultura de massa e cultura popular: leituras operárias. Petrópolis: Vozes, 1986.

CORBIN, A. L’Avènement des loisir (1850-1960). Paris: Aubier, 1995.

ELIAS, N. A sociedade dos indivíduos. Rio de Janeiro: ZAHAR, 1984. Tradução: Vera Ribeiro.

HABERMAS, J. Teoria de la acion comunicativa. Madri: Taurus, 1987.

LUCENA, R. O esporte na cidade: aspectos do esforço civilizador brasileiro. Campinas: Autores Associados, 2001.

MARQUES, R.; GUTIERREZ, G.; ALMEIDA, M. O esporte contemporâneo e o modelo de concepção das formas de manifestação do esporte. Conexões. v.6, n.2, p.42-61, maio/ago. 2008.

MORIN, E. Cultura de massa no século XX: neurose. 9. ed. Rio de janeiro: Forense Universitária, 1997.

NICHOLLS, G. The role of sport counseling for unemployed young people on probation. World leisure e recreation. v. 39. n. 4, p.23-26, 1997. 
STIGGER, M. Participação popular na gestão espaço público de lazer: um caminho percorrível na construção da utopia democrática. In: MARCELLINO, N. (Org.). Políticas Públicas e setoriais de lazer: o papel das prefeituras. Campinas: Autores Associados, 1996. p.177-133.

WEBER, M. Economia e sociedade: fundamentos da sociologia compreensiva. 3. ed. Brasília: Editora Universidade de Brasília, 1994. Tradução de Regis Barbosa e Karen Elsabe Barbosa. Revisão técnica de Gabriel Cohn. 